\title{
Sociology of Labour and Human Resource Management: An Interdisciplinary Approach
}

\author{
Nikova Donka \\ PhD, Associate Professor, Department of Economic Sociology \\ University of National \& World Economy, Bulgari; Email: donka_tsioutsiou@yahoo.com \\ Aspridis George
}

PhD, Associate Professor, Department of Business Administration Technological Educational Institute of Thessaly, Greece; Email: aspridis@teilar.gr

Koffas Stefanos

PhD, Lecturer, Department of Social Work, Frederick University, Cyprus Email: Koffas@gmx.de

Doi:10.5901/ajis.2015.v4n3s1p69

\section{Abstract}

Since Administrative Science approach the various aspects of management in a multidimensional fashion, they derive their scientific background from other sciences, such as mathematics, economics, sociology, anthropology, psychology. Taking into consideration the financial crisis afflicting modern societies, the proposal aims to offer modern operational techniques that regard the human factor as the driving force of the enterprise and thereby contribute significantly to the identification of core labour problems and of effective policies to address them. At the same time, it endeavours to contribute to the systematic study of human behaviour in the workplace. This paper aims to highlight the melding of these two disciplines in the context of the theory of systems, theory of decisions, organizational culture, job satisfaction and the evaluation and management of sensitive social groups. The proposal aims to fill a big gap, present in Greek and Bulgarian literature, concerning the linking of the fields of Human Resource Management and Sociology. This paper presents reflections that could develop modern labour relations and promote the link between sociology and human resource management. The proposal is based on the study of written evidence, using, on the one hand, the historical method to link human resource management with sociology and, on the other, the comparative method in order to highlight the similarities of labour structures. The motive to pursue this subject was both scientific and the authors' personal interest. The conclusions of this paper are very important and any utilization will contribute to the improvement of labour and human relations in the globalized business environment.

Keywords: Human Resource Management, Sociology, Employee Relations, Entrepreneurial Environment, Human Relations.

The human resources management is prevision for the future and every management decision is an act in the future.

\section{Introduction}

Administrative Science is a special branch of the social sciences. During its evolution and especially after World War II, Administrative Science, in order to better study the phenomenon of administration, was influenced but also adopted concepts and methods from a multitude of different related disciplines such as Sociology, Economics, Law, Political Science, Biology, History, Psychology and others (Chevallier, 1993). Its focus would, at times, be on different approaches depending on social trends, in order to determine the component parts and the essence of the administrative phenomenon in its totality (Katsaros, 2008).

The result of the above was the emergence of new "approaches" to the administrative phenomenon, of which the most known are mathematics, H. Simon's decision theory, as well as the study of human behaviour in the context of the enterprise's social system. Among the supporters of the latter are a number of distinguished scientists such as $\mathrm{Ch}$. Barnard, McGregor, Herzberg, Argyris, March-Simon and others. Another approach is the systems theory of S. Beer, and Johnson - Kast - Rosenzweig who study the enterprise as an open socio-technical system that can be managed with the help of computerized decision-making models (Papadakis, 2007).

It was Weber who contributed to the convergence of sociology and Administrative Science. Weber's approach 
shaped the modern organizational theory, which concluded the big discourse between the two sciences (Katsaros, 2008; Chevallier, 1993). The interdisciplinary approach to the problems of Administrative Science allows us to form spherical knowledge on it and at the same time to become a science/crossroads, which is based on pluralism and diversity (Chevallier, 1993).

The current proposal seeks to study how the fields of Human Resource Management and Sociology of Labour converge. However, over the last years the Departments of Sociology of universities study and treat, more intensively, this subject too. It is the convergence of the two disciplines in the light of systems theory, organizational culture, job satisfaction, evaluation and vulnerable social groups. In the midst of a global financial crisis, continuous changes in society, changes in the administration of the human factor, the proposal aims to recommend techniques which consider the human factor the driving force of the enterprise and to contribute to the identification of labour problems and of effective policies to address them. The convergence is effected through examples, but also through the theoretical approach to the subject.

\section{Literature Review}

\subsection{Sociology}

The term was used for the first time by A. Comte in 1839 and refers to society and its study at a higher level. In general, sociology is the science that studies the composition, operation and transformation of society, as well as the social contexts and the consequences of the emergence, upholding, change and waning of social phenomena (Vasiliou et al, 2009).

A. Giddens (1989 : 35) defines sociology as a "social science that focuses primarily on the study of social institutions, brought into being by the industrial transformation of the past two or three centuries".

Sociology deals with the study of social interaction, but also of group behaviour, through research, which is governed by thorough and organized collection of data and their analysis. Through research, sociologists endeavour to understand social interaction and group behaviour, but they also design studies on specific issues in order to evaluate public policy or to inform the general public on existing social conditions (Hughes et al, 2014).

Sociology is distinguished between microsociology, which studies all that people report, do and think in their everyday life and macrosociology which studies large scale organizations, institutions and others. This distinction does not mean that the two levels are independent of each other; quite the opposite (Hughes et al, 2014).

The science of sociology is considered the systematic, analytical or abstract, reflective study of human society. Its fundamental starting point is the relationship of the individual and society (Tsakiris, 2009). Sociology is divided into several branches depending on the social groups or social structures treated by each separate branch. Indicatively, we mention Sociology of Community Organization, Social Movements, Sports and many others (Tsakiris, 2009).

\subsection{Sociology of Labour}

Sociology of labour is a distinct branch of sociology applied in the domain of labour and is concerned with subjects such as the workplace as a social system, working conditions, racial relations and the relationships between groups at the enterprise level and many others (at the website http://eurovoc.europa.eu/drupal/?q=Iv/request\&view=pt\&termuri= http://eurovoc.europa.eu/201969\&language=el).

Organizations, groups, group processes are the constituent parts of the social context within which the workers of the modern industrial world move. Employment is an integral part of social institutions and the type of work affects the social status and the prestige of people (Hughes et al, 2014).

Sociology of labour, as a distinct branch of sociology, approaches all labour issues in a globalized economy. Its specialists deal with work and the way it is organized. At the beginning of the new millennium labour relations are changing dramatically for a multitude reasons; e.g. new technologies, new organizational models and the globalized economy (Tsakiris, 2009; Konstantopoulou, ny; Hughes et al, 2014; Papanis et al, 2005).

Sociology of labour deals with issues concerning the theory of employment, the division of labour, the technological determination, unemployment, spare time, the facets of employment in the mature industrial society, the crisis of employment, labour relations, the relationships of employers and employees and the hierarchy in the workplace (Tsakiris, 2009; Konstantopoulou, ny; Hughes et al, 2014; Papanis et al, 2005; at the website http://www.yourarticlelibrary.com/ 
sociology/social-consequences-of-division-of-labour-sociology/8549/).

In industrial society professional employment is organized according to the system of standardized full-time occupation. Beck considers that the standardization of work is based on the uniformity of the job location, the working hours, but also legal conditions (Morel et al, 2014). A classic in the study of industrial sociology was the American sociologist G.C. Homans (Morel et al, 2014).

\subsection{Human Resource Management (HRM)}

HRM refers to the policies, practices and systems which affect the behaviour, attitudes and performance of workers (Brewster et al, 2007). The major management practices of human resources are about job analysis and planning, programming, recruitment, selection, training and development, remuneration policy, performance management and, finally, internal communication (Noe et al, 2009). From the entirety of managerial duties, HRM deals with the practices and policies required to attend to matters related to personnel issues. Very similar to Noe et al (2009), Dessler (2012) includes here, among others, the recruitment, training, evaluation, remuneration, and the provision of an ethical and just environment.

According to Werther et al (1989: 9) "the purpose of HRM is to improve the productive contribution of people to the organization". According to Gomez-Mejia et al (2012 : 616) "a human resource strategy refers to a firm's deliberate use of human resources to help it gain or maintain an edge against its competitors in the marketplace. It is the grand plan or general approach an organization adopts to ensure that it effectively uses its people to accomplish its mission".

According to Dessler (2012) Administrative Science draws upon knowledge from anthropology and also the study of societies, which contributes to the knowledge on human beings and their activities; also from sociology which studies people in relation to other people. Administrative Science is specifically addressed by two branches of sociology: political sociology and sociology of organizations (Chevallier, 1993).

\section{The Link between Sociology of Labour and Human Resource Management}

\subsection{The systemic approach, the theory of organizations and the hierarchy}

We are born into organizations

We are trained by organizations

And most of us spend

Our entire life working for organizations

A. Etzioni, $1974^{1}$

The theories of $\mathbf{M}$. Weber had a significant contribution to human resource management, which can be summarized in the following:

- The economic behaviour of people in the organization is rational.

- People's rational economic behaviour in the organization enables the marginal efficiency of the activity.

- The rational economic behaviour is achieved by the existence of a strict hierarchy in the organization.

- Human resource management has its basic principles.

The bureaucratic-sociological model of Weber is often regarded as a theory that presents the management of human resources in the organization in an idealized form (Hughes et al, 2014; Morel et al, 2014).

Many are those who have considered the organization a form of domination. The most renowned sociologists who studied the phenomenon were $\mathbf{M}$. Weber and $\mathbf{R}$. Michels. The former defined three types of social domination which could be transformed into legitimate forms of authority : charismatic, traditional and rational domination. He considered that those in control will subdue the people and as a result bureaucracy would turn into an iron cage. The latter developed the theory of the "Iron Law of Oligarchy", according to which organizations end up being dominated by small groups (Morgan, 2000).

Luhmann defined the theory of self-referential social systems, which is not a closed system, but has internalized the aspects of the environment that allow it to maintain its character. At the same time it is different from an open system because it has no direct contact with its social environment. He also defined the concept of the process which ensures 
conflict control and the weakening of the participants in a conflict by transforming their motives (Luhmann, 1995).

Parsons established the AGIL schema which delineated an internal and an external dimension in relation to the environment, but also the internally and externally motivated relationships of inflow and outflow in the internal environment. The structural elements of AGIL refer to the "Adaptation" (A), "Goal attainment" (G), "Integration" (I) and "Latent pattern maintenance" (L) (Hughes et al, 2014; Morel et al, 2014).

Modern organizations are far more flexible and adjust easily to the requirements of each time. For instance, IBM considers the standard organization of a human resources department into subsystems (selection, training and development, evaluation, labour relations and others) inappropriate. Hence, IBM reorganized the functions of the HR department by dividing its 330.000 employees into administrative and technical, managerial and operational staff. The specialists help the employees of each group to have access to the knowledge, training and remuneration required (as cited by Dessler, 2012).

Dahrendorf promoted the division of social conflicts in two dimensions. The first referred to the extent of social units and the second to the class relationship within these units. For example, we can see that within groups of an enterprise there is conflict between older and newer members, between the Board of Directors and the members of the enterprise, while there are also conflicts between enterprises. Quite often it has been observed that colleagues are on bad terms, they cannot cooperate and are constantly arguing (Hughes et al, 2014; Morel et al, 2014). Research has established that workers, as a reaction, reduced their performance and at the same time moved their workspace in order to distance themselves from the person and conflict situations (Gavriil, 2013).

When Durkheim refers to the division of labour he considers it in regard to performance for the satisfaction of an organization's need, in order to increase its efficiency (Hughes et al, 2014; Morel et al, 2014).

\subsection{Evaluation and job performance and remuneration policies}

According to Parsons, the workers' capacity for performance is the means of the action system, which is based on the personalities of the workers. The skills of the workers are not inherent, but are shaped by the social milieu and the cultural models prevalent during each period; they are also cultivated through the educational process (Morel et al, 2014).

For example, the evaluation system of state employees in Greece ought to take into consideration the particularities of the Greek public administration, the peculiar state-employee culture, as well as the rapid socioeconomic developments that have converted the body of state employees exceptionally inflexible to major administrative changes (Aspridis et al, 2014). The performance evaluation of the human resources is part of the organizational culture and ought to be understood by all the workers. Its goal should be the development of the human resources instead of their dismissal, in order for the staff to be willing to participate in such a process (Stergiou, ny).

Homans defined five propositions of behaviourist learning theory, which are linked to theories of worker motivation. More specifically, he referred to the success proposition, the stimulus proposition, the value proposition, the units of reward proposition and, finally, to the unfortunate coincidences. The outcome is that when a person's energy is not rewarded as expected, then he becomes angry and within this context the outcome of aggressive behaviour may offer him some reward. If the worker is not rewarded he will get angry and, indeed, his anger will be proportionate to his past reward (Morel et al, 2014).

A characteristic example was mentioned during an in-house training seminar of an enterprise. More specifically, a business based in Volos had rewarded its employees with productivity bonuses during the holiday seasons. When it realized that the workers could produce more units during their work hours, it abandoned the reward policy and increased the number of daily work units they had to produce.

Marx ascertained that in the modern industrial society alienated labour has the role of forced labour; i.e. labour does not serve any need and causes economic alienation from both the product and the production process, as well as alienation from the species being and other workers (Hughes et al, 2014; Morel et al, 2014).

Societies and working conditions transform and as a result changes in the way human resources are managed emerge. Dessler's (2012 : 32) example of the "generation Y" is characteristic; i.e. young workers that adopt different values towards work in relation to their parents. Older workers focus more on work rather than family when they have to take career decisions. Younger workers tend to focus more on family or find a balance between family and work. Fortune magazine wrote that "generation $Y$ " workers bring challenges and opportunities, while they might become "the most highmaintenance workforce in the history of the world". Many enterprises teach their directors to provide feedback and recognition to young workers. However, the latter, being accustomed to the use of computers and electronic messaging, will also be the most highly productive (Dessler, $2012: 32$ ). 
A. Miller's play "Death of a Salesman" highlights the fact that enterprises use and exploit their workers, getting what they desire and consequently throw away the rest or even dismiss them because they are not needed (Morgan, 2000).

\subsection{Flexible forms of work and harmonization of personal-professional life}

From a sociological standpoint, the theory of F. Taylor contributed to human resource management the following main points : the implementation of a system for the effective use of the physical capabilities of the human body, the introduction of the principle "order - control", the study of the interaction between the two factors of the labour process "man - machine" with subsequent recommendations, the application of the "engineering approach" in human resource management, etc (Pachev et al, 2007).

The theory of F. Taylor on human resource management has its social importance (Pachev et al, 2007). At the macro level the increase of productivity of labour is seen as a social aim which leads to the reduction of poverty. At the mezzo level it offers procedures for the adaptation of human resources to the production system and new values and relationships between employees and employers. At the micro level it introduces a new image of the worker as a personality who is not isolated but works jointly in a group and participates in the development of the organization. His professional progress and qualifications are prerequisites for rising in the hierarchy of the organization. Additionally, the concept of organizational structure is a product of Taylorism (Taylor, 2007; Pachev et al, 2007).

Looking at Mayo's theory from a sociological perspective, one may summarize its main contributions to human resource management as follows:

- Affirming values of the industrial society.

- Development of the idea of the human being as a social individual and not only an economic individual, who needs both the technical knowledge and the social skills required at a new workplace, organization or profession.

- The thesis of a new type of manager who also needs social skills.

- The analysis of the relationship "individual - group".

- The thesis of the informal structure, informal relationships, the informal leader of the organization, etc. U.S.A. enterprises reward the individual's effect on company results and remuneration is determined according to market dynamics. In Europe, enterprises focus on and reward the capabilities and responsibilities of each role (Gomez-Mejia et al, 2012; Aspridis, 2012; Mayo, 1946).

The human relations model of Elton Mayo is a theory of human resource management in the organization which is often considered "sociological romanticism" (Gomez-Mejia et al, 2012; Aspridis, 2012).

The modern ideas (concepts) on the management of human resources are a result of the changes that have occurred in the organization. They have aspects of great sociological importance. Large contemporary organizations are difficult to manage and are therefore less efficient. The strict hierarchization becomes an obstacle to their development. Therefore, it is required to decentralize and form organizations with fewer but highly qualified staff, and modern technologies and technical means. The basic needs of such organizations would include i) the scientific selection, preparation and verification of the skills and abilities of each member of the organization, ii) forming a common idea of the objectives and perspectives of the organization in all organizational members, iii) developing and implementing effective material and social incentives such as remuneration, recognition of merit, promotion prospects at work, professional education, parenting in professionalism, etc (Gomez-Mejia et al, 2012).

According to Armstrong (1993), some of the fundamental principles of human resource management in modern organizations are:

- Human resources are the most important asset and their effective management is the key to success.

- This success becomes possible only if the company's workforce policy and procedures are connected and contribute the most to the achievement of corporate goals and strategic plans.

- The corporate culture, values, climate and the management's behaviour have a major influence on the effort to achieve improvement and perfection.

- All members of the organization should participate and work with the consciousness of a common goal.

The primary objectives of human resource management in modern organizations that stand out in sociological literature are the development of professionally qualified personnel who correspond to the needs of the organization and also the creation of optimal conditions for the most complete and expedient use, renewal and development of professionally qualified staff. This basic objective of human resource management breaks down into a system of 
derivative targets which are related to the management of : i) the recruitment process of human resources needed by the organization, ii) motivation, iii), the quality of performance, iv) the remuneration of work, v) the education, training and development of human resources, vi) working conditions, and vii) relationships (Gomez-Mejia et al, 2012).

Viewed from a sociological perspective, the well-known, in our days, Japanese model is prominent among modern concepts and models on the management of human resources. According to Pachev (Pachev et al, 2007), the main characteristic of this model is to ensure the connection between the results of the production activity and the long-term goals of the organization. The employees should not be forced to work but should be provided with the appropriate conditions for labour activity. These conditions include the relationship between education and employment in the company, wages, social insurance, rise in the hierarchy, and participation of the personnel in the ownership, management and profits of the organization (Papalexandris et al, 2002).

Over the past years and especially after the suicides at France Telecom, a dialogue began on the relationship of sociology and the formation of opinion regarding the individual and his self in the workplace environment (Karakioulafi, 2013; Loriol, 2007; Markowitz, 1997).

Technology changes the nature of work. In older factories, machine operators manually controlled machines which transformed pieces of metal into mechanical parts. In our days, the workers tap commands into machines controlled by computers and manufacture precision parts for water pumps and other similar products. That is why human resources managers recently declared "critical thinking/problem solving" and "information technology applications" as the two skills which will most likely be the most important over the next five years (Dessler, $2012: 30$ ).

L.L. Bean, an American clothing and outdoor activity equipment chain store, offers competitive remuneration and a full benefits package, such as cash performance bonuses, health and insurance coverage, and pension plans. When the online sales of the company exceeded the telephone ones, the company closed four call-centres, but made sure that its 220 employees worked from home. Instead of creating jobs overseas, it has maintained the job positions near the town where L.L. Bean started the company 100 years ago. Like many other employers today, the company is utilizing effective human resource management practices in order to maintain an edge against its competitors (Dessler, $2012: 21$ ).

In Greece, the lack of balance between personal and professional life is quite pronounced as Greeks, at least comparatively, work longer hours. Greek enterprises display a delayed response to the required changes. Many workers consider that they are in a position to understand and achieve the balance between personal and professional life. The lack of balance affects the worker's mental state, both in the family environment and workplace (Aspridis, 2012).

The Japanese model of human resource management maintains that the organizations should fist invest in their human resources and then in the creation of capital and technologies. In the Japanese consciousness, the economic organization is both a productive institution and a social institution and is the guarantor of the workers' and their families' existence. Labour activity is paramount in their life. The Japanese model of human resource management in organizations is an attempt to combine traditions with modern scientific achievements and social practice. It is based on the concept of the indissoluble connection between the coalition of the organizational members and the success of the organization and is one of the reasons for the interest in this model and its importance to sociology (Pachev et al, 2007).

\subsection{Racial and ethnic approaches to labour}

Feminist sociology endeavours to study the position of women, gender relations, the inferiority of women and their capabilities as fundamental topics (Morel et al, 2014). Younger women suffer more bullying and/or harassment than their male colleagues. The number of women that become targets of sexual harassment is triple that of men. In the E.U. of 27 , approximately $50 \%$ of all female workers are in the lower pay scales. This can be explained by the fact that a larger proportion of women work part-time. However, the differences are pronounced even between full-time workers (at the website http://www.eurofound.europa.eu/sites/default/files/ef_files/pubdocs/2006/52/el/1/ef0652el.pdf). In general, women work in part-time jobs, are less mobile professionally, are paid less, are more often treated unfairly, remain unemployed for longer etc. It is characteristic that neither Weber nor Marx attached any importance to the unpaid work of women. The most major representative of the feminist movement, $\mathbf{R}$. Becker-Schmidt considers that the inferior position of women is related to their social position in the capitalist system (Morel et al, 2014).

The ethnic approach to labour focuses on social relations during the production process, the cultural perception of labour as a means to construct an identity and assign meaning, the relationship of the community with occupation and unemployment, as well as the manner in which work is structured and effected in organizations (Hughes et al, 2014; Wallman, 1976). In this context, the E.U. has issued directives that prohibit direct or indirect discrimination based on racial or ethnic origin, religion or beliefs, disability, age and sexual orientation. Lately, changes have been observed in the legislation of the EU member-states as a result of adopting these directives (Council Directive 2000/43/EC). 


\section{Conclusions}

The essence of human resource management, according to the sociological bibliography, is usually defined as a conscious human activity for organizing and regulating the relations between organizational members to achieve current and prospective organizational goals. Human resource management is the management of the organization's most valuable asset. The organization, through its members, achieves a stable competitive advantage. Therefore they are considered a valuable asset in which to invest and hence increase their intrinsic value.

The successful management of the human resources of every organization requires as a condition that the policy and management procedures should be a function of the corporate objectives and practical tasks of the organization, and should contribute to the greatest possible extent to the implementation of those objectives. Additionally, the economic and social interests, and needs of the human resources should be equal to the needs and interests of the organization.

From a sociological perspective, human resource management has its own specifics since i) the object (human resources) is multi-structured, highly dynamic and depends multilaterally on internal and external factors of the organization. The human resources are characterized by an extremely wide variety of individualities. These are personalities with different mentalities, interests, attitudes, age etc, ii) the human resources are simultaneously the object and subject of management, iii) it requires the management of a large number of social processes with heterogeneous origin, iv) there is a hierarchy.

According to sociological literature, the concepts and models of human resource management in the organizations can be summarized in two main groups with great sociological importance : classic and modern.

\section{References}

Andreeva, M. 2014. Human Resources Management. Veliko Turnovo : Faber. (In Bulgarian).

Armstrong, M. 1993. Human Resources Management. Burgas : Delfinpress (In Bulgarian).

Aspridis, G. 2012. The new technologies and their impact on the work-life balance during crisis. Book of proceedings of ESDO, Larissa, 25-27/5/2012 (23-38). (In Greek).

Aspridis, G., Rossidis, I. and Falaras, E. 2014. Opinion paper of the Administrative Chamber of Greece on the evaluation of state and municipal employees. Available online at http://www.poeota.gr/anakoinoseis/SYGNAJ10-7-2014.pdf. [Accessed on 10 August 2015] (In Greek).

Batzias, Fr., Blesios, N., Naxakis, Ch., Terzidis, K., Katsalis, A. and Michalopoulos, N. 2008. Introduction to the Administration of Enterprises and Organizations - Basic Principles of Organization and Management, vol. A, 2nd edition, Patra : HOU. (In Greek).

Brewster, C., Sparrow, P. and Vernon, G. 2007. International Human Resource Management. $2^{\text {nd }}$ edition, London : CIPD.

Chevallier, J. 1993. Administrative Science. Athens-Komotini : A. N. Sakoulas. (In Greek).

Dessler, G. 2012. Human resources management - Basic concepts and modern trends. Athens : Kritiki. (In Greek).

Dimitrov, D. 2000. Sociology of Work. Sofia. IPK Racio-90. (In Bulgarian).

European Commission. Council Directive 2000/43/EC of 29 June 2000 implementing the principle of equal treatment between persons irrespective of racial or ethnic origin. Formal Journal, No. L 180 of 19 July 2000, pp. 0022-0026.

Gavriil, D. 2013. "How much drama can we take?" Presentation of the book of K. Cloke and J. Goldsmith. Synygoros, vol. 10. (In Greek).

Giddens, A. 1989. Introduction to Sociology. Athens : Odysseas. (In Greek).

Gomez-Mejia, R. L., Balkin, D., and Cardy, R. 2012. Managing Human Resources. $7^{\text {th }}$ edition, NY : Pearson.

Grint, K. 2005. The Sociology of Work. Cambridge : Polity Press.

Hughes, M., and Kroehler, C. 2014. Sociology - The core. Athens : Kritiki. (In Greek).

Karakioulafi, Ch. 2013. "Psychosocial risks at the workplace: An interpretation from the scope of sociology of labour - The example of the France Telecom suicides". Istorin, 13. Available online at http://www.historein.gr/2011/05/france-telecom.html. [Accessed on 9 August 2015].

Katsaros, I. 2008. Organization and Management of Education. Athens : Pedagogical Institute. (In Greek).

Konstantopoulou, Ch. ny. For a Sociology of Labour. Thessaloniki : Paratiritis. (In Greek).

Loriol, M. 2007. "Sociology of work facing up to new pathologies: Stress, burnout, harassment". Social Cohesion and Development 2 (1) $(79-91)$.

Luhmann, N. 1995. Theory of Social Systems. Athens - Komotini : A. N. Sakkoulas. (In Greek).

Markowitz, G. 1997. "Sociological approaches to labour relations and new technologies: The relationship between technology and culture". Thesis, vol. 60. Available on line at http://www.theseis.com/index.php?option=com_content\&task=view\&id=588. [Accessed on 9 August 2015]. (In Greek).

Mayo, E. 1946. The Human Problems of Industrial Civilization. Cambridge : Harvard University Press.

Morgan, G. 2000. Images of organization. Athens : Kastaniotis. (In Greek).

Noe, R., Hollenbeck, J., Gerhart, B., and Wright P. 2009. Human Resources Management: Gaining a competitive advantage. Athens : 
Papazisis. (In Greek).

Pachev, T., and Kolev, B. 2007. Economic Sociology. Sofia : Stopanstvo. (In Bulgarian).

Papadakis, V. 2007. Corporate Strategy: The Greek and International Experience. Athens : Benos. (In Greek).

Papalexandris, N., and Bourantas, D., 2002. Human Resource Management. Athens : Benos. (In Greek).

Papanis, E. and Rontos, K. 2005. Psychology - Sociology of Labour and Human Resources Management - Theory and Empirical Research. Athens : Sideris. (In Greek).

Stergiou, N. ny. "Personnel Evaluation". Available online at http://www.e-psychology.gr/work-psychology/451-occupational-psychologyemployee-evaluation.html. [Accessed on 11 August 2015]. (In Greek).

Taylor, Fr., 2007. The principles of scientific management. Athens : Papazisis. (In Greek).

Tsakiris, A. 2009. "What is Sociology?" Available online at https://tsakthan.wordpress.com/2009/03/08/\%CF\%84\%CE\%B9-\%CE\%B5\% CE\%AF\%CE\%BD\%CE\%B1\%CE\%B9-\%CE\%BA\%CE\%BF\%CE\%B9\%CE\%BD\%CF\%89\%CE\%BD\%CE\%B9\%CE\%BF\%CE\% BB\%CE\%BF\%CE\%B3\%CE\%AF\%CE\%B1/. [Accessed on 22 July 2015]. (In Greek).

Vasiliou, Th. and Stamatakis, N. 2000. Dictionary of Human Science. Athens : Gutenberg. (In Greek).

Wallman, S., (Ed.). 1976. Social Anthropology of Work. London: Academic Press.

Werther, B.W., and Keith, D. 1989. Human Resources and Personnel Management. NY: McGraw-Hill.

\section{Internet Sources}

http://www.yourarticlelibrary.com/sociology/social-consequences-of-division-of-labour-sociology/8549/, [Accessed on 22 July 2015]. (In Greek).

http://eurovoc.europa.eu/drupal/?q=Iv/request\&view=pt\&termuri=http://eurovoc.europa.eu/201969\&language=el, [Accessed on 22 July 2015]. (In Greek).

http://www.eurofound.europa.eu/sites/default/files/ef_files/pubdocs/2006/52/el/1/ef0652el.pdf, [Accessed on 11 August 2015]. (In Greek). http://www.bg-ikonomika.com/2011/04/upravlenie-na-choveshkite-resursi.html, [Accessed on 23 August 2015]. (In Bulgarian). 